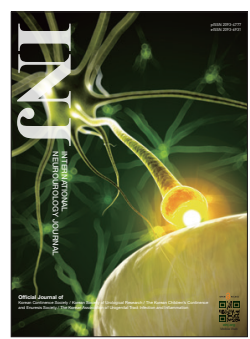

\title{
Overactive Bladder is a Distress Symptom in Heart Failure
}

\author{
Youn-Jung Son ${ }^{1}$, Bo Eun Kwon ${ }^{2}$ \\ ${ }^{1}$ Red Cross College of Nursing, Chung-Ang University, Seoul, Korea \\ ${ }^{2}$ Seoul Women's College of Nursing, Seoul, Korea
}

\begin{abstract}
The prevalence of Heart failure (HF) is expected to increase worldwide with the aging population trend. The numerous symptoms of and repeated hospitalizations for HF negatively affect the patient's quality of life and increase the patient's economic burden. Up to $50 \%$ of patients with HF suffer from urinary incontinence (UI) and an overactive bladder (OAB). However, there are limited data about the relationship between UI, OAB, and HF. The association between HF and urinary symptoms may be directly attributable to worsening HF pathophysiology. A comprehensive literature review was conducted for all publications between January 2000 and November 2017 using the PubMed, Embase, and Cochrane databases. HF represents a major and growing public health problem, with an increased risk of UI and an OAB as comorbidities. Possible effects of HF on urinary problems may be mediated by the prescription of medications for symptomatic relief. Although diuretics are typically used to relieve congestion, and angiotensin-converting enzyme inhibitors and angiotensin receptor blockers improve survival, these classes of drugs have been suggested to worsen urinary symptoms in the presence of HF. Further research is required to understand the impact of $\mathrm{UI}$ and an $\mathrm{OAB}$ on the HF illness trajectory.
\end{abstract}

Keywords: Heart failure; Urinary incontinence; Overactive urinary bladder; Prevalence; Comorbidity

- Fund/Grant Support: This study was supported by Seoul Women's College of Nursing in 2015 (SNJC 2015-007).

- Conflict of Interest: BEK, a member of the Editorial Board of INJ, is the correspinding author of this article. However, she played no role whatsoever in the editorial evaluation of this article or the decision to publish it. No potential conflict of interest relevant to this article was reported.

\section{INTRODUCTION}

Heart failure (HF) is a complex clinical syndrome characterized by the reduced ability of the heart to pump and/or fill with blood [1]. HF has been defined as a global pandemic, since it affects around 26 million people worldwide [2]. The prevalence of HF is expected to rise because of the aging population, improvements in the treatment of diagnosed HF, and marked increases in the prevalence of predisposing risk factors such as hypertension and diabetes [1]. In South Korea, the number of patients with HF has been increasing in recent years, with an average annual increase rate of 4.5\% from 2009 to 2013 [3]. In addition, HF is one of the leading causes of death in South Korea [4]. With a rapidly aging population in South Korea, it is expected that the prevalence of $\mathrm{HF}$ and its associated costs will continue to increase. HF is characterized by recurrent episodes of exacerbation often preceded by gradually deteriorating fluid status. When it is not adequately assessed and managed, symptoms of volume overload and congestion may eventually develop, which frequently necessitate hospitalization for acute decompensated HF [5].

Urinary incontinence (UI) is defined by the International Continence Society as any involuntary leakage of urine [6]. The overactive bladder $(\mathrm{OAB})$, characterized by urinary urgency, frequency, nocturia, and/or urge incontinence, is common in

Corresponding author: Bo Eun Kwon (iD https://orcid.org/0000-0002-8748-1171 Seoul Women's College of Nursing, 38 Ganhodae-ro, Seodaemun-gu, Seoul 03617, Korea

E-mail: bekwon@snjc.ac.kr / Tel: +82-2-2287-1736 / Fax: +82-2-395-8018

Submitted: March 21, 2018 / Accepted after revision: June 7, 2018 
older adults and may be negatively associated with quality of life [7]. Since UI and OAB is an age-related condition, significantly more patients present with concomitant cardiovascular (CV) comorbidities (e.g., hypertension) compared with non-OAB patients [8], which emphasizes the importance of evaluating the CV safety of OAB pharmacotherapies. Also, these comorbid conditions share multiple risk factors such as obesity, diabetes, hypertension, smoking, and advanced age [9]. Particularly, the association between HF and urinary symptoms may be directly attributable to deteriorating HF pathophysiology; however, medications used to treat HF may also indirectly provoke or exacerbate urinary symptoms. For more than half a century, diuretics have been the only drugs that rapidly and efficiently modulate hypervolemia, and these are widely used in patients with HF to correct and maintain optimal fluid status. Because fluid retention and peripheral edema in patients with HF usually necessitate the administration of diuretics, these patients are also likely to experience changes in urinary frequency [10]. However, whether risk factors and medication including diuretics are associated with symptoms of $\mathrm{UI}$ and $\mathrm{OAB}$, and worsening quality of life due to HF has not been well-studied $[6,11]$. Therefore, we conducted this review to compile the existing data on this topic and identify the scope for further studies in this field.

\section{LITERATURE SEARCH}

In this review paper, the articles were identified through the main databases related to health, including the PubMed, Embase, and Cochrane databases to identify English-language peer-reviewed studies published between January 2000 and November 2017. To avoid excluding potential articles, a comprehensive search using both key words and similar terms was conducted. Search terms included "urinary incontinence," "overactive bladder," "urinary symptoms or bladder," "nocturia," and "heart failure."

\section{PREVALENCE AND SIGNIFICANCE OF URINARY INCONTINENCE AND OVERACTIVE BLADDER IN HEART FAILURE}

UI is associated with reduced functional capacity in patients with HF [12]. Studies indicate that $35 \%-50 \%$ of patients with HF suffer from UI [13-15]. Although urinary symptoms may antedate the diagnosis of HF, urinary urgency with or without incontinence is found to be 2.9 times more prevalent in patients with New York Heart Association (NYHA) class III or class IV
HF compared with class I or class II [10]. One study reported that $32 \%$ of men and $41 \%$ of women with chronic HF experience UI [16]. In another study reporting the cooccurrence of chronic diseases and geriatric syndromes in the 2004 wave of the Health and Retirement Study, UI was reported by $36.7 \%$ of respondents who also reported having HF [15].

The natural history of OAB in HF patients is not understood. A recent study reported that $34.1 \%$ of HF patients experience moderate/severe OAB symptoms, and $43.5 \%$ experience moderate/severe lower urinary tract symptoms compared with the age-matched controls [17]. Another study also revealed that the occurrence of $\mathrm{OAB}$ symptoms was $57 \%$ in patients with chronic HF, although the rate of nonurgent incontinence and urinary frequency and nocturia was $10 \%$ and $19 \%$, respectively [10]. However, few patients seek medical treatment for their OAB [10]. It should be noted that patients with chronic HF with $\mathrm{OAB}$ may exhibit more severe cardiovascular comorbidities, including hypertension, pulmonary heart disease, cerebrovascular disease, renal disease, and diabetes [18].

Urgency incontinence is associated with a sudden, compelling urge to void, and often coexists with other symptoms of $\mathrm{OAB}$ such as frequency, urgency, and nocturia [19]. Unfortunately, many of the bladder control problems experienced by patients with HF may not be cured [20]. Despite this, assessment and treatment by continence or HF healthcare professionals may help reduce patients' problems to a more manageable level and improve the quality of life and survival rates in HF.

\section{MECHANISMS AND RISK FACTORS OF URINARY INCONTINENCE AND OVERACTIVE BLADDER IN HEART FAILURE}

Direct precipitation of urinary problems in HF may be due to compensatory secretion of natriuretic peptides [20]. Natriuretic peptides play an important role in the body's regulation of intravascular volume by promoting excretion of sodium and elimination of bodily fluids. Brain natriuretic peptide (BNP) has been widely studied in relation to cardiac load, with levels typically rising and falling in association with the severity of HF symptoms. Released from ventricular cardiomyocytes in response to an increase in ventricular wall tension, BNP has been shown to fluctuate in parallel with hemodynamic measures such as left ventricular end diastolic pressure. High BNP levels have been independently associated with the presence and severity of nocturnal voiding, as well as nocturnal polyuria in elderly 
patients [21]. Redistribution and elimination of fluid from peripheral or pulmonary edema further contribute to urinary frequency and excessive diuresis, especially overnight when peripheral edema is resorbed in the supine position [12].

NYHA classification in HF is used to grade the severity of functional limitations of patients and estimate how far they are able to walk before becoming breathless [22]. NYHA class I represents no symptoms, class II represents symptoms during ordinary activities, class III represents symptoms with minimal exertion, and class IV represents symptoms at rest. In patients with NYHA III-IV symptoms, reduced functional capacity and decreased mobility are important risk factors for UI, as both impede the ability to reach the toilet in a timely manner during episodes of urinary urgency [10].

$\mathrm{OAB}$ may be a component of a neurohormonal phenomenon that includes HF, fatigue, and depression [10]. Emerging evidence in the fields of neurocardiology and behavioral cardiology exists to suggest that HF and depression share signs such as decreased heart rate variability and symptoms including low mood and fatigue, and researchers suggest they may also share the same mechanism [23,24]. An association between depression and urge incontinence has been reported with depression in $60 \%$ of those who have idiopathic urge incontinence [25]. However, the mechanism underlying this relationship is not clear. Choi et al. [26] found decreased heart rate variability in women in $O A B$, leading them to suggest that $\mathrm{OAB}$ symptoms may be indicators of disease or dysfunction in the autonomic nervous system. These findings indicate that further research is needed to better understand the relationship among $\mathrm{HF}$, depression, and $\mathrm{OAB}$.

With regard to risk factors of UI and OAB in HF, effects of both acute and chronic HF on the lower urinary tract may be mediated by the prescription of medications for both tertiary prevention and symptomatic relief [27]. Drug therapy in HF is essential for slowing disease progression and for the improvement of symptoms and survival [11]. However, as a part of their modes of action or as side effects, many of these medications can iatrogenically contribute to urinary frequency, urgency, nocturia, or incontinence [17]. Additionally, many of the risk factors for UI are the same as those for HF, such as advanced age, obesity, obstructive sleep apnea, and diabetes [10,12]. Particularly, patients with chronic HF could harbor several coexisting illnesses, such as hypertension, diabetes, pulmonary disease, and stroke [10]. These comorbidities are also reportedly associated, at least in part, with urologic symptoms in the general population [28-30]. However, there have been few studies on the frequency and severity of incontinence in patients with HF.

\section{HEART FAILURE MEDICATIONS THAT WORSEN URINARY INCONTINENCE AND OVERACTIVE BLADDER}

Diuretics are part of the first-line treatment for symptomatic relief of HF [31]. These drugs increase sodium urinary excretion and decrease physical signs of fluid retention [31]. Nonetheless, by causing diuresis or increased formation of urine by the kidneys, diuretics increase urinary frequency and may cause urinary urgency and incontinence [32]. While discontinuation of diuretics may lead to "decompensation and relapse" in patients with HF, it is reasonable to reduce the dose after acute congestion has been cleared and the patient is stable [12]. However, whether diuretic use is associated with symptoms of $\mathrm{OAB}$ and worsening quality of life has not been well-studied [28]. The role of diuretics in the development of $\mathrm{OAB}$ in patients with $\mathrm{HF}$ is still a matter of debate because fluid overproduction related to diuretic use may not cause urgency, which is the cardinal symptom of OAB. However, Ekundayo et al. [33] showed that loop diuretics may increase the prevalence of $\mathrm{OAB}$ in aged adults. Diuretic-induced rapid production of urine may add urgency to diuretic-associated high urinary frequency.

Angiotensin-converting enzyme (ACE) inhibitors are standard therapy for patients with HF with symptomatic left ventricular systolic dysfunction [12]. They have been shown to reduce morbidity and mortality in clinical trials; however, there is less evidence for treatment with ACE inhibitors in all patients with HF [34]. Although ACE inhibitors are generally well-tolerated, they are associated with a persistent cough probably caused by increased levels of bradykinin and tachykinin [12]. The ACE inhibitor-induced cough is characterized by being dry, non-productive, and worse at night [35], and occurs in 5\%-35\% of patients receiving ACE inhibitors [36]. This cough can produce or exacerbate stress incontinence by increasing urethral pressure [12]. Angiotensin receptor blockers (ARBs) for ACE inhibitors are "equal, in terms of reduction of mortality and morbidity in HF patients," but ARBs do not induce the cough that can cause UI in patients treated with ACE inhibitors [12].

Beta-blockers have been extensively studied in the treatment of HF, and are standard treatment for improvement of clinical outcomes in patients with HF [37]. There is a chronic activation of the sympathetic nervous system in HF in an attempt to restore cardiac output. This is a compensatory mechanism that provides 
inotropic support to the failing heart by increasing stroke volume and peripheral vasoconstriction. In the context of incontinence, emerging evidence suggests that $\beta$-blockers may increase bladder contractility and provoke symptoms of urinary urgency $[38,39]$. The effects of $\beta$-blockers on the risk of incontinence are, however, inconsistent and require further investigation.

\section{NONPHARMACOLOGICAL MANAGEMENT OF URINARY INCONTINENCE AND OVERACTIVE BLADDER IN HEART FAILURE}

Lifestyle change is the first step in the management of urinary problems in HF [14]. Namely, conservative management strategies for the treatment of urinary symptoms, such as fluid management, avoidance of caffeinated beverages, and regular performance of pelvic floor muscle exercises should be prioritized as first-line treatment [12,27].

Fluid restriction represents a key management strategy in patients with chronic HF $[21,27]$. An individualized fluid management program is recommended for each patient according to the severity of HF, renal function, and other dietary behaviors. Clinically, 1.5-2 L of fluid intake per day is recommended for most patients and an intake greater than $2 \mathrm{~L}$ per day is generally discouraged [14]. Dietary modifications include the reduction or elimination of caffeinated beverages, which increase urinary urgency and enhance diuresis [27]. Excessive sodium and alcohol consumption should be avoided, as both have a deleterious impact on HF [40]. Use of compression stockings during the day by stable chronic HF patients may help prevent distal leg edema, nocturnal fluid redistribution, and nocturnal urinary frequency and urgency $[41,42]$. Intensive, pelvic floor muscle exercises, under the supervision of a physical therapist, have been shown to have "clinically important effects" in reducing urine leakage and yield equivalent or superior efficacy to pharmacotherapy with fewer negative effects [27].

\section{PHARMACOLOGICAL MANAGEMENT OF URINARY INCONTINENCE AND OVERACTIVE BLADDER IN HEART FAILURE}

Antimuscarinics represent the most commonly prescribed drugs of $\mathrm{OAB}$ and are generally considered to be 'safe' drugs [43]. But there are most common adverse cardiac effects related to the use of antimuscarinics such as increase in heart rate and QT interval prolongation [44].
According to a recent review [44], it is difficult to recommend a standardized clinical surveillance of HF patients when treated with antimuscarinics for OAB symptoms. Therefore, clinical and electrocardiography monitoring may be considered in older patients with HF.

To date, mirabegron, a $\beta 3$-adrenoceptor agonist, and the first in its class for the treatment of $\mathrm{OAB}$ symptoms, offers an efficacious and safe alternative to first-line treatment in patients intolerant to antimuscarinics $[45,46]$. With regard to the cardiovascular safety of mirabegron, it seems to be good and comparable with that of antimuscarinic agent [45]. However, there are limited data on the use of mirabegron for treating OAB symptoms in HF. Accordingly, further studies are needed to understand the impact of antimuscarinics and mirabegron in patients with HF.

\section{CONCLUSIONS}

$\mathrm{UI}$ and $\mathrm{OAB}$ are prevalent in patients with HF. Advanced or endstage $\mathrm{HF}$, fatigue, depression, increased heart rate, and diuretic use are associated with the development of UI and OAB in HF. Moreover, several types of HF medications affect the bladder and its ability to function properly. $\mathrm{UI}$ and $\mathrm{OAB}$ incontinence can affect health-related quality of life and health status in patients with HF. Additionally, patients with HF may become depressed and be afraid to socialize and enjoy usual activities due to urinary problems. It can also cause prolonged sedentary behaviors or weight gain, which increase the burden on the heart.

Accordingly, urology and HF health professionals should be aware that it is important to assess or monitor urinary problems after HF diagnosis and evaluate the severity of UI and $\mathrm{OAB}$ during the HF illness trajectory.

\section{REFERENCES}

1. Tan LB, Williams SG, Tan DK, Cohen-Solal A. So many definitions of heart failure: are they all universally valid? A critical appraisal. Expert Rev Cardiovasc Ther 2010;8:217-28.

2. Palmer MH, Busby-Whitehead J. Relationship between heart failure and overactive bladder. Curr Bladder Dysfunct Rep 2010;5:1822.

3. Lee H, Oh SH, Cho H, Cho HJ, Kang HY. Prevalence and socioeconomic burden of heart failure in an aging society of South Korea. BMC Cardiovasc Disord 2016;16:215.

4. Korean National Statistical Office. The annual statistical report of 
the cause of death 2014. Daejeon (Korea): Statistics Korea; [cited 2016 Mar 1]. Available from: http://www.index.go.kr/potal/main/ EachDtlPageDetail.do?idx_cd=1012.

5. Retrum JH, Boggs J, Hersh A, Wright L, Main DS, Magid DJ, et al. Patient-identified factors related to heart failure readmissions. Circ Cardiovasc Qual Outcomes 2013;6:171-7.

6. Bartoli S, Aguzzi G, Tarricone R. Impact on quality of life of urinary incontinence and overactive bladder: a systematic literature review. Urology 2010;75:491-500.

7. Sexton CC, Coyne KS, Thompson C, Bavendam T, Chen CI, Markland A. Prevalence and effect on health-related quality of life of overactive bladder in older americans: results from the epidemiology of lower urinary tract symptoms study. J Am Geriatr Soc 2011;59:146570.

8. Andersson KE, Sarawate C, Kahler KH, Stanley EL, Kulkarni AS. Cardiovascular morbidity, heart rates and use of antimuscarinics in patients with overactive bladder. BJU Int 2010;106:268-74.

9. Bouwman II, Voskamp MJ, Kollen BJ, Nijman RJ, van der Heide WK, Blanker MH. Do lower urinary tract symptoms predict cardiovascular diseases in older men? A systematic review and metaanalysis. World J Urol 2015;33:1911-20.

10. Palmer MH, Hardin SR, Behrend C, Collins SK, Madigan CK, Carlson JR. Urinary incontinence and overactive bladder in patients with heart failure. J Urol 2009;182:196-202.

11. Altunoluk B, Kankilic N, Nacar AB, Bulut BB., Akkoyun M, Bahar $\mathrm{MR}$, et al. Relationship between the use of diuretics and overactive bladder in patients with heart failure. J Clin Anal Med 2014;5:1079.

12. Tannenbaum C, Johnell K. Managing therapeutic competition in patients with heart failure, lower urinary tract symptoms and incontinence. Drugs Aging 2014;31:93-101.

13. Hwang R, Chuan F, Peters R, Kuys S. Frequency of urinary incontinence in people with chronic heart failure. Heart Lung 2013;42:2631.

14. Lindeman K, Li Y, Palmer MH. Help-seeking for incontinence by individuals with heart failure. J Am Geriatr Soc 2012;60:1994-5.

15. Lee PG, Cigolle C, Blaum C. The co-occurrence of chronic diseases and geriatric syndromes: the health and retirement study. J Am Geriatr Soc 2009;57:511-6.

16. Bierman AS. Coexisting illness and heart disease among elderly Medicare managed care enrollees. Health Care Financ Rev 2004;25:105-17.

17. Chiu AF, Liao CH, Wang CC, Wang JH, Tsai CH, Kuo HC. High classification of chronic heart failure increases risk of overactive bladder syndrome and lower urinary tract symptoms. Urology 2012;79:260-5.
18. Rosa GM, Baccino D, Valbusa A, Scala C, Barra F, Brunelli C, et al. Cardiovascular effects of antimuscarinic agents and beta3-adrenergic receptor agonist for the treatment of overactive bladder. Expert Opini Drug Saf 2018;17:487-97.

19. DuBeau CE, Kuchel GA, Johnson T 2nd, Palmer MH, Wagg A; Fourth International Consultation on Incontinence. Incontinence in the frail elderly: report from the 4th International Consultation on Incontinence. Neurourol Urodyn 2010;29:165-78.

20. Kim HN, Januzzi JL Jr. Biomarkers in the management of heart failure. Curr Treat Options Cardiovasc Med 2010;12:519-31.

21. Yoshimura K, Nakayama T, Sekine A, Matsuda F, Kosugi S, Yamada $\mathrm{R}$, et al. B-type natriuretic peptide as an independent correlate of nocturnal voiding in Japanese women. Neurourol Urodyn 2012; 31:1266-71.

22. Raphael C, Briscoe C, Davies J, Ian Whinnett Z, Manisty C, Sutton $\mathrm{R}$, et al. Limitations of the New York Heart Association functional classification system and self-reported walking distances in chronic heart failure. Heart 2007;93:476-82.

23. Lesman-Leegte I, Jaarsma T, Sanderman R, Linssen G, van Veldhuisen DJ. Depressive symptoms are prominent among elderly hospitalised heart failure patients. Eur J Heart Fail 2006;8:634-40.

24. Grippo AJ. Mechanisms underlying altered mood and cardiovascular dysfunction: the value of neurobiological and behavioral research with animal models. Neurosci Biobehav Rev 2009;33:17180.

25. Zorn BH, Montgomery H, Pieper K, Gray M, Steers WD. Urinary incontinence and depression. J Urol 1999;162:82-4.

26. Choi JB, Kim YB, Kim BT, Kim YS. Analysis of heart rate variability in female patients with overactive bladder. Urology 2005;65:1109-12.

27. Yu CJ, Hsu CC, Lee WC, Chiang PH, Chuang YC. Medical disease affecting lower urinary tract symptoms. Urol Sci 2013;24:41-5.

28. Fitzgerald MP, Link CL, Litman HJ, Travison TG, McKinlay JB. Beyond the lower urinary tract: the association of urologic and sexual symptoms with common illnesses. Eur Urol 2007;52:407-15.

29. van Gerwen M, Schellevis F, Lagro-Janssen T. Comorbidities associated with urinary incontinence: a case-control study from the Second Dutch National Survey of General Practice. J Am Board Fam Med 2007;20:608-10.

30. Coyne KS, Kaplan SA, Chapple CR, Sexton CC, Kopp ZS, Bush EN, et al. Risk factors and comorbid conditions associated with lower urinary tract symptoms: EpiLUTS. BJU Int 2009;103 Suppl 3:24-32.

31. Faris R, Flather MD, Purcell H, Poole-Wilson PA, Coats AJ. Diuretics for heart failure. Cochrane Database Syst Rev 2006;(1):CD003838.

32. Yip GW, Wang M, Wang T, Chan S, Fung JW, Yeung L, et al. The 
Hong Kong diastolic heart failure study: a randomised controlled trial of diuretics, irbesartan and ramipril on quality of life, exercise capacity, left ventricular global and regional function in heart failure with a normal ejection fraction. Heart 2008;94:573-80.

33. Ekundayo OJ, Markland A, Lefante C, Sui X, Goode PS, Allman RM, et al. Association of diuretic use and overactive bladder syndrome in older adults: a propensity score analysis. Arch Gerontol Geriatr 2009;49:64-8.

34. Kazi D, Deswal A. Role and optimal dosing of angiotensin-converting enzyme inhibitors in heart failure. Cardiol Clin 2008;26:114.

35. Hall SA, Chiu GR, Kaufman DW, Wittert GA, Link CL, McKinlay JB. Commonly used antihypertensives and lower urinary tract symptoms: results from the Boston Area Community Health (BACH) Survey. BJU Int 2012;109:1676-84.

36. Segall L, Nistor I, Covic A. Heart failure in patients with chronic kidney disease: a systematic integrative review. Biomed Res Int 2014;2014:937398.

37. Foody JM, Farrell MH, Krumholz HM. beta-Blocker therapy in heart failure: scientific review. JAMA 2002;287:883-9.

38. Ruby CM, Hanlon JT, Fillenbaum GG, Pieper CF, Branch LG, Bump RC. Medication use and control of urination among community-dwelling older adults. J Aging Health 2005;17:661-74.

39. Lewandowski J, Sinski M, Symonides B, Korecki J, Rogowski K, Ju- dycki J, et al. Beneficial influence of carvedilol on urologic indices in patients with hypertension and benign prostatic hyperplasia: results of a randomized, crossover study. Urology 2013;82:660-5.

40. Klatsky AL. Alcohol and cardiovascular diseases: where do we stand today? J Intern Med 2015;278:238-50.

41. Partsch H. Compression therapy: clinical and experimental evidence. Ann Vasc Dis 2012;5:416-22.

42. van der Wal MH, van Veldhuisen DJ, Veeger NJ, Rutten FH, Jaarsma T. Compliance with non-pharmacological recommendations and outcome in heart failure patients. Eur Heart J 2010;31:1486-93.

43. Andersson KE, Campeau L, Olshansky B. Cardiac effects of muscarinic receptor antagonists used for voiding dysfunction. $\mathrm{Br} J \mathrm{Clin}$ Pharmacol 2011;72:186-96.

44. Rosa GM, Bauckneht M, Scala C, Tafi E, Leone Roberti Maggiore U, Ferrero $S$, et al. Cardiovascular effects of antimuscarinic agents in overactive bladder. Expert Opin Drug Saf 2013;12:815-27.

45. Rosa GM, Ferrero S, Nitti VW, Wagg A, Saleem T, Chapple CR. Cardiovascular safety of $\beta 3$-adrenoceptor agonists for the treatment of patients with overactive bladder syndrome. Eur Urol 2016; 69:311-23.

46. Thiagamoorthy G, Kotes S, Zacchè M, Cardozo L. The efficacy and tolerability of mirabegron, a $\beta 3$ adrenoceptor agonist, in patients with symptoms of overactive bladder. Ther Adv Urol 2016;8:38-46. 